\title{
Nascent Professional Identity Development in Freshman Architecture, Engineering, and Construction Women
}

\section{Dr. Andrea Nana Ofori-Boadu, North Carolina A\&T State University}

Dr. Andrea N. Ofori-Boadu is an Assistant Professor of Construction and Construction Management with the Department of Built Environment within the College of Science and Technology at North Carolina Agricultural and Technical State University (NCA \& T). Her research interests are in bio-derived cement replacement materials, delivery of sustainable built environments, and professional identity development in architecture, engineering and construction (AEC) students.

In February 2019, Andrea received the prestigious National Science Foundation NSF - CAREER award to research professional identity development processes in undergraduate AEC women. She has also received grants from East Coast Construction Services, Engineering Information Foundation, and the National Association of Home Builders. Dr. Ofori-Boadu was selected to participate in the 2019 QEM-NSF INCLUDES summit. In 2018, she was selected as a 2018 National Science Foundation - NC A \& T ADVANCE IT Faculty Scholar. She also received the 2018 CoST Teaching Excellence Merit Award. Dr. Ofori-Boadu received both the 2017 NC A \& T - CoST Rookie Research Excellence Award and the 2017 North Carolina A \& T State University (NCAT) Rookie Research Excellence Award. Under her mentorship, Dr. Ofori-Boadu's students have presented research posters at various NCAT Undergraduate Research Symposia resulting in her receiving a 2017 Certificate of Recognition for Undergraduate Research Mentoring. In 2016, her publication was recognized by the Built Environment Project and Asset Management Journal as the 2016 Highly Commended Paper. Andrea has served as a reviewer for the National Science Foundation (NSF), Environmental Protection Agency (EPA), and several journals and conferences.

In 2015, Dr. Ofori-Boadu established her STEAM ACTIVATED! program for middle-school girls. She also serves as the Executive Vice-President of Penuel Consult, Incorporated. She is married to Victor Ofori-Boadu and they are blessed with three wonderful children.

\section{Mr. Victor Ofori-Boadu, Penuel Consult Inc.}

Victor Ofori-Boadu is a seasoned Strategic Business Analytics Consultant and the President of Penuel Consult Inc. He holds two Master's Degrees in Agricultural Economics and Accounting. He has a wide range of experience in market research, advance analytics, measurements, evaluation and monitoring and business intelligence. Victor has worked on several research and business projects that have resulted in grants, publications, and presentations. The dissemination of his research findings have contributed to the implementation of agricultural outreach programs and policies that have been of benefit to stakeholders.

\section{Mr. Jacob Randall Vanderpool, North Carolina Agricultural and Technical State University}

Junior Construction Management Student at North Carolina Agricultural and Technical State University President of NAHB Student Organization

\section{Dongyang Deng, North Carolina Agricultural and Technical State University}

Ph D: Civil Engineering, West Virginia University, 2017 BS: Environmental Science, China University of Mining and Technology , 2008

Research interests: Trace level contaminants removal from aqueous phase; physical, chemical and biological wastewater treatment technology development; shale gas fracturing flow back water remediation and reuse; advanced surface characterization and analysis; Chemical spill and fate in the environment; Environmental microbiology; sustainable resource and energy development. 


\section{Nascent Professional Identity Development in Freshman Architecture, Engineering, and Construction (AEC) Women}

Increasing the persistence of talented women into male-dominated architecture, engineering, and construction (AEC) professions could reduce prevailing workforce shortages and improve gender diversity in AEC industry. Identity theorists advocate that professional identity development (PID) improves students' persistence to become professionals. However, little empirical research exists to inform and guide AEC educators and professionals on AEC-PID in undergraduate AEC women. As the preliminary part of a larger nationwide and longitudinal research study investigating PID processes in undergraduate AEC women, the objective of this research is to examine the characteristics and nascent AEC-PID in 69 women enrolled in freshman AEC courses in five U.S. institutions. A purposive sampling approach ensures participants have a wide range of demographic characteristics. Data from a recruitment survey is analyzed using the NVivo qualitative data analysis software. Content and relational inductive open coding are conducted vertically for each participant and horizontally across different participants.

Results indicate passion/interest, inherent abilities, significant others, benefits from industry, and desire to contribute to industry influence decisions to pursue AEC careers. With 52\% of participants having science, technology, engineering, art, and math (STEAM) subject preferences, an in vivo code, Perfect Middle Ground, demonstrated the quest to combine STEM and visual art preferences in AEC career decisions. A participant noted that 'this major (civil engineering) is the perfect middle ground because I can be creative, but still use my strong gift which happens to be math'. Girls with STEAM strengths and passion, particularly in math and fine art, are most likely to develop nascent AEC-PID. Beyond STEM pre-college programs, AEC educators should consider recruiting from sports, as well as visual and performing arts events for pre-college students. Participants' positive views focus on the importance and significant societal impact of the AEC industry; while, negative views focus on the lack of gender and racial diversity. A combination of participants' AEC professional experiences and views reveal four increasing levels of nascent AEC-PID which are categorized as the 4Ps: Plain, Passive, Progressive, and Proactive. As a guide to AEC education and professional communities, recommendations are made to increase the AEC-PID of women in each category. With the highest nascent AEC-PID, women in the Proactive category should serve as leaders in AEC classrooms and student organizations. Considering their AEC professional experience and enthusiasm, they should serve as peer mentors to other students, particularly AEC women. Furthermore, they should be given the opportunity to step into more complex roles during internships and encouraged to pursue co-op opportunities.

Insights can guide more targeted recruitment, mentoring, preparation, and retention interventions that strengthen the persistence of the next generation of AEC women professionals. In the long term, this could reduce AEC workforce shortages, improve gender diversity, and foster the innovation and development of more gender friendly AEC products and services.

Introduction

An 11\% construction employment growth from 2016 to 2026, making the severe workforce shortages of the construction industry a nationwide crisis (Building Design and Construction, 
2016; U.S. Department of Labor, 2018; McGraw Hill Construction, 2012; Choi, Shrestha, Lim, \& Shrestha, 2018). Although women talents could contribute to resolving this national crisis, according to United Nations Educational, Scientific and Cultural Organization (2017), women continue to remain the most untapped population for the next generation of STEM professionals. In fact, the National Association for Women in Construction (NAWIC, 2018) reported that women make up $9 \%$ of the construction workforce, and women professionals are only $2.8 \%$ of this workforce. Considering that over $50 \%$ of the world's population is made up of women, the stronger persistence of women into the AEC profession could reduce workforce shortages, improve gender diversity, and enhance the innovation and development of more gender friendly AEC products and services. Women underrepresentation in engineering and technology professions is not due to their lack of cognitive ability, but as a result of the socialization and learning processes which influence their identities and career choices (Ofori-Boadu, 2018a; Ofori-Boadu, 2018b; Porter \& Ofori-Boadu, 2018). Cultural stereotyping and negative imagery such as dirty hands, old boys' network, and negative female images discourage younger girls from making career choices that lead into male-dominated STEM professions (Phipps, 2001). While wide gender gaps in STEM fields such as biology no longer exist, women are still underrepresented in AEC professions. Interventions that improved women's participation in some STEM professions may not have been as effective with AEC professions, because they are not robust enough to overcome the unique characteristics of the AEC profession.

Undergraduate AEC programs to include architectural engineering, civil engineering, and construction management prepare students to work in the innovation, development, and management of buildings and structures. In addition to AEC curriculum, extracurricular programs strengthen pre-college and college interests and persistence into AEC careers (OforiBoadu et al., 2019a; Ofori-Boadu et al., 2019b; Ofori-Boadu et al., 2019c; Ofori-Boadu et al., 2017). Effective and targeted transformations in AEC educational and professional environments could improve female PID and persistence into AEC professions (Ofori-Boadu et al., 2019a; Ofori-Boadu et $a l ., 2019 \mathrm{~b}$ ). However, very little is known about PID in undergraduate AEC women who are in the process of becoming AEC professionals. There is minimal empirical knowledge to guide decision makers in targeted strategies that will strengthen AEC-PID in undergraduate women. The current theory-practice gap which exists in many male-dominated undergraduate programs can be bridged with PID research on the process of internalization whereby undergraduate women students come to think, act, and feel like professionals.

Theoretical Framework

The theoretical framework for this research has its foundation in psychology and sociology literature (Burke \& Stets, 2009). Identity theorists advocate that an understanding of PID processes lead to targeted policies and programs that improve students' persistence into various professions. PID is the process by which students come to think, act, and feel like professionals (Cruess et al., 2015). It is the successful integration of personal attributes and professional training in the context of a professional community. It is an ongoing process of interpretation and re-interpretation of experiences which allow the strengthening and maturing of an individual through a series of processes of professional education and experiences (Beijaard, 2004; Kerby, 1991; Kogan, 2000). Multiple factors within and outside the educational and professional 
environment impact the evolution and progression of an individual's professional identity (Cruess et al., 2015).

Researchers have examined how students view themselves as participants in various STEM programs and how various constructs interact to contribute to students' PID (Capobianco, 2006; Ofori-Boadu, 2018b). The professional identities of students enrolled in specific STEM programs is constantly evolving as a result of students' multiple self-identities that interact with academic and professional environments (Capobianco, 2006). Gee (2001) highlights the four perspectives of identity to include: (1) nature identity; (2) institution identity; (3) discourse identity; and (4) affinity-identity. Gee's model guides investigations on how students' multiple identities interact with academic and professional programs and institutional contexts as students mature and transition to think, feel, and become professionals. Helm (1998) emphasizes that the beliefs, values, wants, and views of individuals regarding what they want to become influences how they interact with those structures and contexts. Identity development is also influenced by cultural and social environments as individuals are shaped by the structures, forms, activities and events that occur within these environments (Holland et al., 1998). Conceptually, PID is congruent with the processes that affect the personal identity development of individuals as they progress through life and continuously organize their experiences into a meaningful whole that incorporates personal, private, public and professional identities (Cruess et al., 2015; Piaget \& Inhelder, 1969; Kohlberg, 1984; \& Kegan, 1982). The complex identity formed as individuals progress from infancy into adulthood is represented by individual, relational, and collective domains (Vignoles, Schwartz, \& Luyckx, 2011). The individual domain focuses on personal characteristics and beliefs, the relational refers to influence from significant individuals like family and friends, and the collective domain reflects on the impact of social groups to which an individual belongs (Cruess et al., 2015).

Drawing from these theoretical foundations, it can be inferred that some undergraduate AEC women may begin their nascent AEC-PID process even before they enroll in an undergraduate AEC program. While this AEC-PID may be weak, it is the source of inspiration that influences AEC program enrollment. Nascent AEC-PID may be influenced by pre-college STEM and AEC knowledge, strengths, experiences, views, and values. Following enrollment, AEC women begin to interact with new academic, professional, and institutional AEC environment. Interactions evolve among multiple identities during the formative years and progresses over time until a more mature AEC professional identity is developed (Ofori-Boadu et al., 2019a). Students who do not have an effective PID progression usually will exit the AEC environment for other options. The PID process is complicated by negative environmental factors which influence the progression and participation of women in male-dominated AEC disciplines. Women often have to employ various strategies and tactics to construct their professional identity and cope in male dominated cultures (Hatmaker, 2013). Negative imagery and cultural stereotyping have a negative impact on the decisions made by young girls and women and limits their career choices into male dominated professions (Phipps, 2002). While research on the interactions between gender and STEM identities have contributed to improvements in women representation in STEM, women are still underrepresented in the AEC profession (Brickhouse, Lowery, \& Schultz, 2000; Brickhouse, 2001; Chinn, 2001, Capobianco, 2006; NAWIC, 2018). The AEC educational and professional community is seeking for strategies to increase women participation. However, there is little empirical knowledge of the characteristics and nascent 
AEC professional identities of undergraduate AEC women. Insights could shed light on how academic and professional environments can be transformed to strengthen AEC-PID and persistence of undergraduate women into male-dominated AEC professions.

Objectives

As the preliminary part of a larger nationwide and longitudinal research study investigating PID processes in undergraduate AEC women, the objective of this paper is to examine the characteristics and nascent AEC-PID in 69 women enrolled in freshman AEC courses in five U.S. institutions. Nascent is defined as 'just coming into existence and beginning to display signs of future potential, especially of a process or organization' (Lexico, 2020). By enrolling in undergraduate AEC programs, all RPs demonstrated nascent AEC professional identities of thinking, acting, and becoming AEC professionals. It is assumed that RPs with pre-college AEC professional experience and views would demonstrate the highest level of nascent AEC-PID. Therefore, a combination of AEC views and professional experiences could be used to categorize nascent AEC-PID in undergraduate AEC women.

Method

The research in this present paper reports on preliminary findings from a larger research study investigating AEC-PID processes in undergraduate AEC women. The overall goal of this fouryear Institutional Review Board (IRB) approved longitudinal research study is to construct grounded theories that explain AEC-PID processes in undergraduate AEC women. Research participants (RPs) are undergraduate AEC women enrolled in freshman AEC programs in five U.S. institutions which are diverse in location, predominantly white institution (PWI)/ historically black college/university (HBCU) status, accreditations, and AEC programs. Purposive maximum variation sampling is used to obtain a broad range of undergraduate AEC women. Data sources are primarily interviews and surveys.

The Grounded Theory (GT) method is selected over ethnography and phenomenology qualitative methodologies because it is cheaper and allows the use of iterative, inductive and interactional processes of data collection with simultaneous analysis and emergent interpretation for constructing theories from empirical data when a theory is not available to explain the process that occurs with time (Charmaz, 2006; Charmaz, 2014). GT surveys, interviews, and document reviews provide detailed descriptions of situations, events, people, interactions, and behaviors. Drawing from the sensitizing concepts, and the relativist ontology, constructivist worldview, and intepretivist epistemology, the constructivist GT methodology was preferred to the alternative positivist classic Glaser and Strauss GT method (Charmaz, 2014; Glaser \& Strauss, 1967; Groen, 2017; Groen et al., 2018; Groen et al., 2017; Grounded Theory Online, 2018).

In this paper, 69 RPs completed recruitment surveys which requested demographic information to include age, GPA, race, annual household income, household size; favorite subjects; leadership and student organization experiences; AEC industrial experiences; country of birth; current extracurricular activities; AEC views; and rationale for AEC enrolment. Data from multiple-choice and open-ended questions are analyzed using the NVivo qualitative software and Microsoft Excel software. Content and relational inductive coding are conducted within each 
participant and across different participants. Although very limited, RPs with missing data for specific survey items are excluded during the analysis of that particular survey item.

Results and Discussions

Characteristics of undergraduate AEC women enrolled in freshman AEC courses

Most of the RPs (98.55\%) are between 18 and 25 years old. This suggests that compared to older women, younger women who are directly from high school or recent transfers from college or university programs, are more likely to enroll in AEC programs. African Americans and Whites are $50.72 \%$ and $36.23 \%$ of RPs respectively. Asians and American Indians/Native Alaskans are $8.70 \%$ and $4.35 \%$ respectively. Most $(95.65 \%)$ of the RPs were born and have lived mostly in the United States. The racial diversity in the research population reflects racial distribution in the U.S. population. Table 1 shows that various financial backgrounds are represented in this study with the highest percentage (29.23\%) from households with annual income exceeding $\$ 101,000$.

Table 1. Annual Household Income

\begin{tabular}{lccccc} 
Annual Household Income (\$) & $\leq \$ 25 \mathrm{~K}$ & $\$ 26 \mathrm{~K}-\$ 50 \mathrm{~K}$ & $\$ 51 \mathrm{~K}-\$ 75 \mathrm{~K}$ & $\$ 76 \mathrm{~K}-\$ 100 \mathrm{~K}$ & $\$ 101 \mathrm{~K} \leq$ \\
\hline Percentage of RPs $(\%)$ & 18.46 & 12.31 & 23.08 & 16.92 & 29.23
\end{tabular}

With almost $70 \%$ of RPs being from households with income being greater than $\$ 50,000$, there is a strong indication that women from middle and high income households are likely to enroll in AEC programs. This is in agreement with the Association of American Colleges and Universities (AACU, 2018) that emphasizes that family income impacts educational enrollment and attainment. Nevertheless, the spread across various household income ranges is reassuring and demonstrates that financial resources are available for women from lower income households. Most RPs are from three to four person households (Table 2). This is slightly different from the 2019 U.S. household distribution which had only $27 \%$ of U.S. households being three to four persons, with one to two person households making up $62 \%$ of U.S. households Statista (2020). In contrast with Statista (2020) which had $8 \%$ of U.S. households being five to six person households, $34.85 \%$ of RPs were from five to six person households.

Table 2. Household Size

\begin{tabular}{lccccc} 
Number of household members & $\leq 2$ & $3-4$ & $5-6$ & $7-8$ & $9 \leq$ \\
\hline Percentage of RPs $(\%)$ & 13.64 & 50.00 & 34.85 & 1.52 & 0.00
\end{tabular}

Most (75.81\%) of the RPs had GPAs ranging from 3.5 to 4.0. This is expected because most AEC programs require high GPA for undergraduate AEC enrollment. Majority (72.46\%) of the RPs did not indicate any political affiliation. It is unclear whether they are truly not politically affiliated or just declined to share that information. The rest of the RPs are Democrats (15.94\%), Republicans (5.80\%), Liberals (4.35\%), and Conservatives (1.45\%).

AEC Programs: Figure 1 shows that $27.54 \%$ of the RPs are enrolled in civil engineering programs, and closely followed by $23.19 \%$ in architecture. Also, $44.93 \%$ are enrolled in architecture related programs and $57 \%$ in engineering programs. Women are better represented 
in architecture and engineering programs, but underrepresented in construction management. Approximately $14.49 \%$ of the RPs are enrolled in dual degrees indicating high intellectual capacity as most institutions have higher requirements for enrollment in dual degree programs.

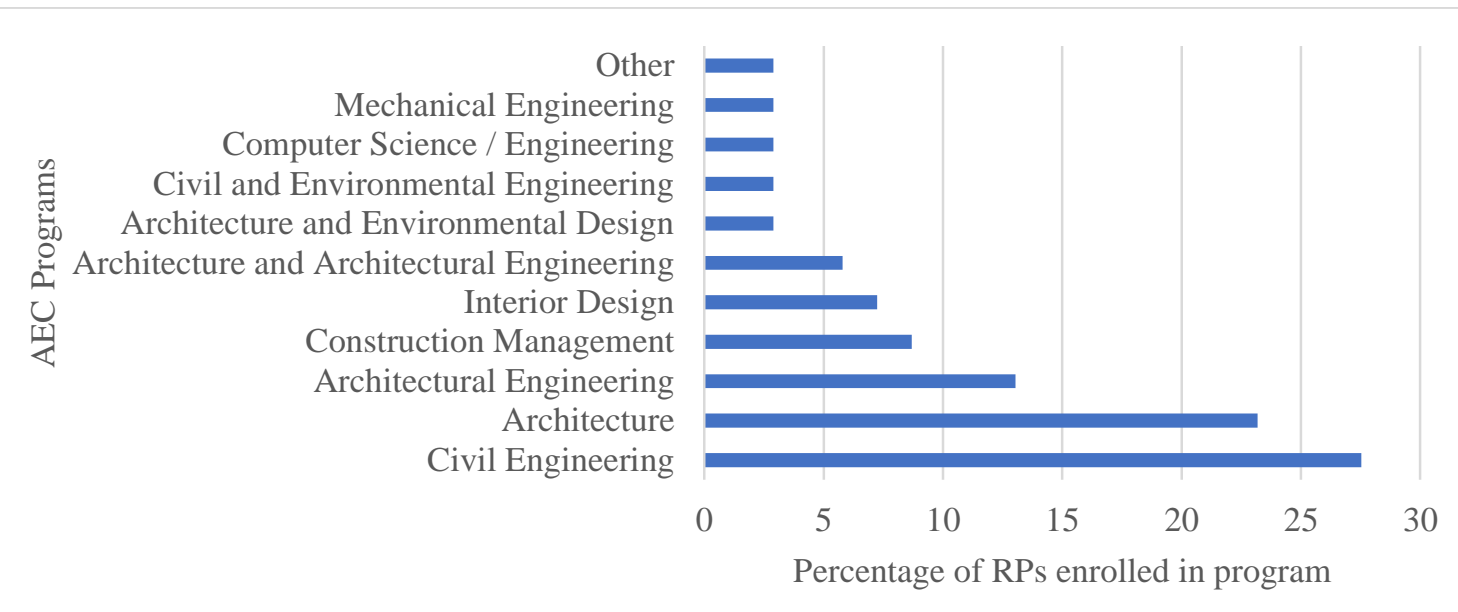

Fig. 1. AEC Programs

Favorite subjects: Math emerged as the most favorite subject as shown in figure 2, with $69.57 \%$ of the RPs and $94.44 \%$ of RPs in engineering programs selecting math as their favorite subject. Although math is a requirement for all AEC majors, $30.43 \%$ of the RPs did not consider math as a favorite subject. While a few of the RPs with lower preference for math are enrolled in civil engineering programs, most of them are in interior design, architecture, and construction management programs which have lower math requirements. This does not necessarily mean that these RPs did not excel in math; it just means math is not their favorite subject.

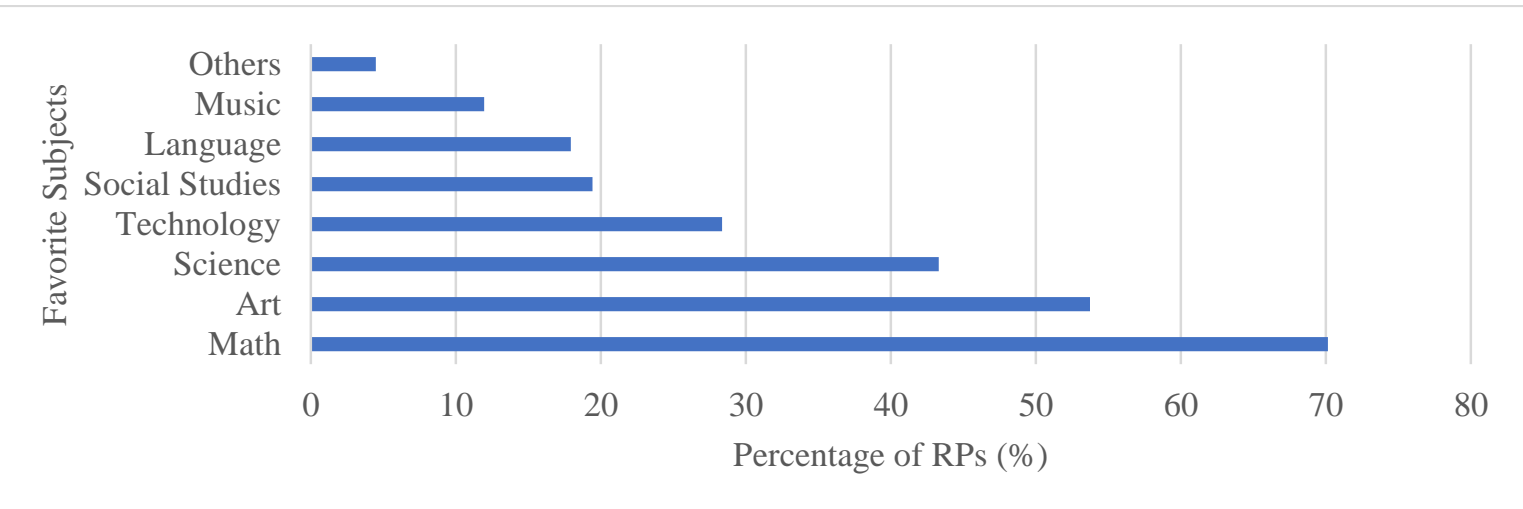

Fig. 2. Favorite Subjects

Art emerged as the second most favorite subject with $53.62 \%$ of the RPs indicating that art is their favorite subject. Most of these RPs are enrolled in architecture, interior design, and civil engineering programs. The design requirements of these programs are high and so it is reasonable that women with preference for art are enrolled in these programs. Surprisingly, $25.81 \%$ of RPs enrolled in architecture related programs and $20 \%$ enrolled in interior design programs did not select art as a favorite subject. Considering that art and design are key components of these programs, follow up studies will assess their experiences in these programs. 
Only $43.48 \%$ of the RPs consider science as a favorite subject. Majority of RPs with science as a favorite subject are in civil engineering, architectural engineering, and architecture programs.

Surprisingly, only $55.56 \%$ of RPs in engineering programs consider science as a favorite subject. Whereas low favorite status does not mean that RPs did not excel in science, it can be agreed that higher favorite status could improve performance. Research in STEM teaching innovations can strengthen science and mathematics subject preferences in pre-college and college women.

Religious Affiliation: Figure 3 shows that majority (60.87\%) of RPs identify with Christianity, with majority being Catholics and Baptists. Religious diversity in this population contribute to the diverse perspectives that inform the findings from this research study.
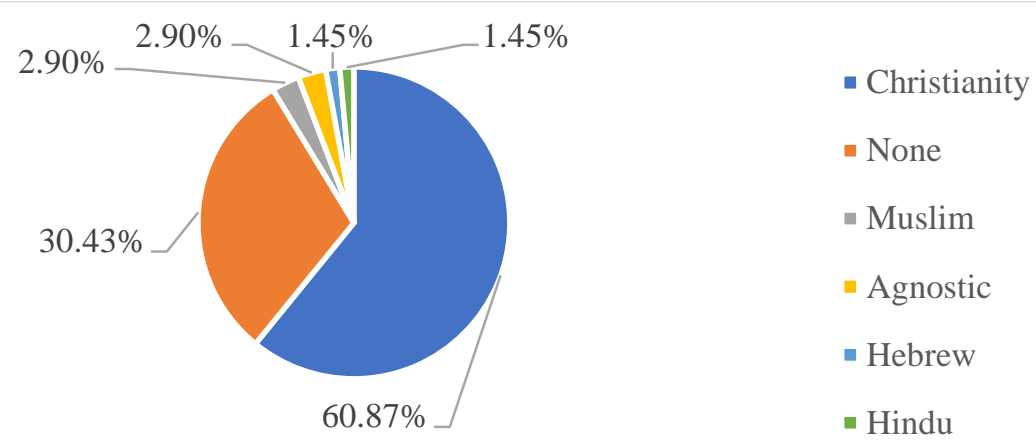

Fig. 3. Religion

Extracurricular Activities: Some RPs are members of student organizations (49.23\%), serve as student leaders (51.56\%), and have some AEC experiences (29.85\%). Figure 4 shows that $69 \%$ of RPs are currently engaged in a variety of extracurricular activities with the average RP having 1.57 extracurricular activities and one RP having as many as seven commitments. Extracurricular commitments were mostly initiated through family networks, student organizations, and community engagements. Notably, $27.54 \%$ are engaged in AEC related activities to include Habitat for Humanity, Society of Women Engineers (SWE), American Society for Civil Engineers (ASCE), International Design Interior Association (IDIA), National Association of Women in Construction (NAWIC) and the National Association of Home Builders (NAHB). Civil engineering women are the most involved in extracurricular activities.

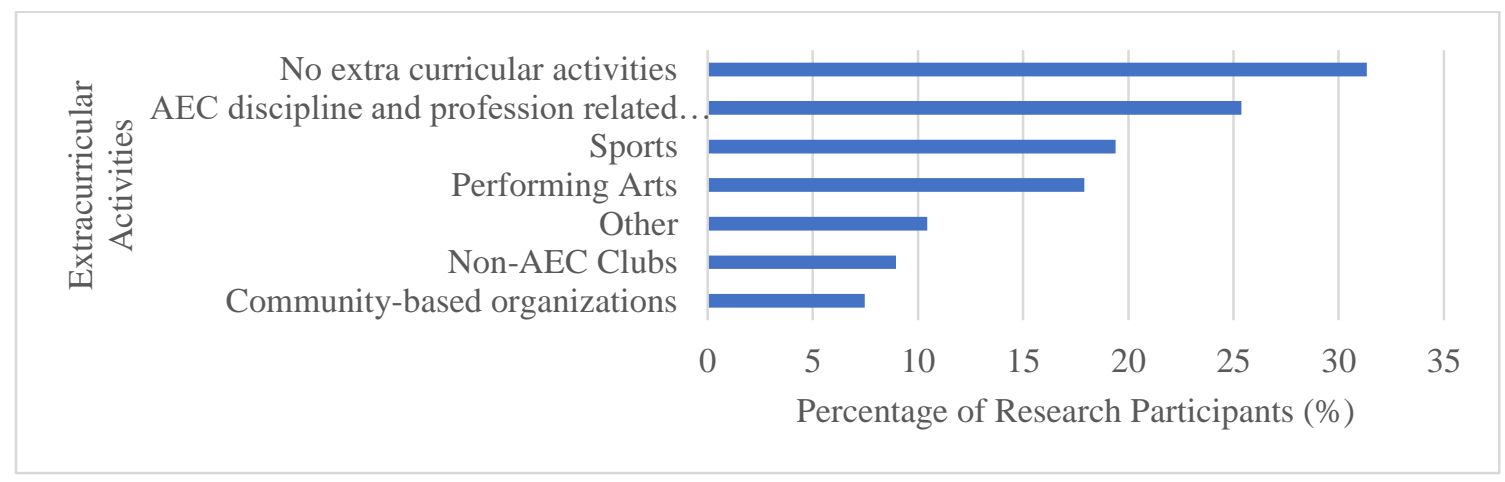

Fig. 4. Extracurricular Activities 
RPs (18.84\%) are involved in sports to include basketball, soccer, and tennis. Also, $17.39 \%$ are engaged in performing arts activities to include choir, poetry and dance. Notably, $10.45 \%$ of the RPs are involved in dance activities to include Ballet and Zumba. In addition to recruiting from pre-college STEM related programs and schools, AEC educators and administrators should seriously consider recruiting students from sports and performing arts events and organizations, as AEC students enjoy physical, outdoor, hands on, fun, and creative activities.

Decision to enroll in undergraduate AEC program: Five themes emerged from RPs responses to rationale guiding their decisions to enroll in undergraduate AEC programs as shown in figure 5. RPs expressed strong passion and interests in AEC professions. Their interests emerged from prior exposure to the AEC industry through sources such as HGTV television programs.

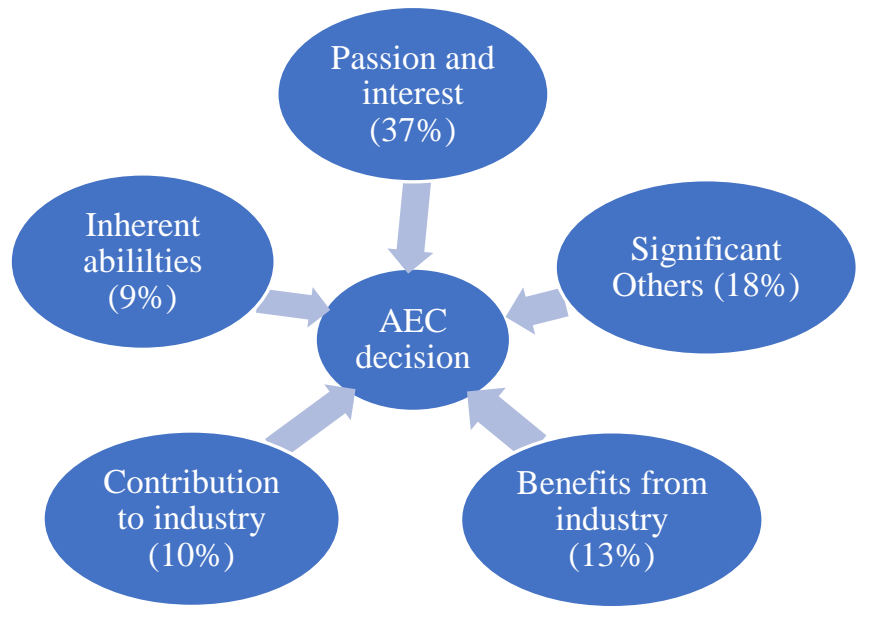

Fig. 5. Decision to enroll in undergraduate AEC programs

Significant others with some associations with the AEC industry influenced some RPs' decisions, while others were motivated by the desire to benefit from the industry through professional development and compensation. The desire to contribute to the industry by building structures, controlling environmental impacts, helping others, and improving gender diversity motivated some RPs to pursue AEC degrees. Also, some RPs pursued AEC degrees as a result of their inherent abilities to include problems solving, creativity, and hands on skills.

Views about AEC industry: While $22.39 \%$ of RPs expressed no views about the industry, many RPs expressed both positive (50.75\%) and negative views (49.25\%) about the AEC industry. Positive comments noted that it is a great and growing industry (31.34\%), has a high impact on everyday lives, tasks, and global societies (10.45\%), and presents lots of opportunities (8.96\%). An RP stated that 'I think the AEC industry is essential to the way we all live our lives and do everyday tasks.' Several RPs are excited about the creative, innovative, and collaborative aspects of the AEC industry and the potential for their generation to contribute to this industry. An RP noted that 'I believe that the AEC industry will improve over the years because of my generation having more technology and techniques to understand the materials and how we can change things.' Similar comments demonstrated RPs' high levels of self-efficacy and strong nascent AEC professional identities with the zeal to obtain an education that will ensure positive transformations in the AEC industry. RPs also liked the fact that AEC professionals enjoy and see the fruit of their labor. Negative comments are associated with the lack of racial (7.46\%) and 
gender (41.79\%) diversity. An RP from an HBCU noted that the AEC industry is 'an amazing and constantly growing industry, but there is a lack of diversity with race and gender.'

Interestingly, a few RPs indicated that they were unaware of the low gender participation until they started taking undergraduate AEC courses. Nevertheless, the RPs expressed the hope that the number of women in the AEC profession will increase as they will continue to work hard to increase women representation.

Nascent AEC-PID Categories (4Ps): As shown in figure 6, the combination of RPs' AEC professional experiences and views of the AEC industry is used to develop four increasing levels of nascent AEC-PID categories captioned as the 4Ps: (1) Plain; (2) Passive; (3) Progressive; and (4) Proactive. As a guide to AEC education and professional communities, recommendations are made to increase the AEC-PID of women in each category.

The $\underline{\boldsymbol{P L A I N}}$ category comprises of $20.90 \%$ of RPs. These women have no AEC experience nor any clearly stated AEC views and so have the lowest nascent AEC-PID. They have enrolled in AEC programs and envisage themselves as having sufficient pre-requisite knowledge, skills, and abilities to successfully progress and graduate to become AEC professionals. AEC women who fall in this category will need additional resources and support from AEC educational institutions to nurture their initial interest and knowledge of the AEC industry to increase their AEC-PID. For example, AEC educators can encourage them to explore AEC publications, videos, websites, and projects to increase their AEC knowledge. Field trips, laboratory, internship, and hands on projects can increase their AEC experience. Also, they should be given opportunities to participate in AEC extracurricular activities and student organizations as these could increase their AEC knowledge and views through their exposure to other AEC students and professionals.

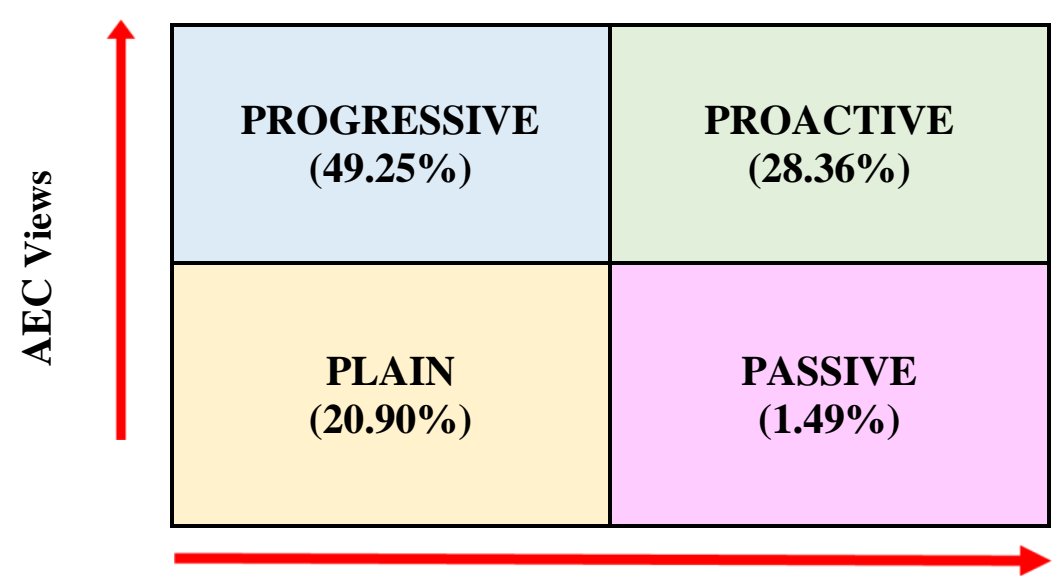

AEC Professional Experience

Fig. 6. Nascent AEC-PID Categories

The $\underline{\boldsymbol{P A S S I V E}}$ category has the lowest RP representation (1.49\%) for women with some AEC experiences, but no AEC views. They are considered passive because it is expected that typically a student with AEC experiences should be capable and willing to share their AEC views.

Consequently, they have the second lowest nascent AEC-PID. It is not clear why they appear unenthusiastic about sharing their AEC views. Future research should focus on why they have 
AEC experiences, but are unwilling to share AEC views. This will provide insights that could help strengthen their AEC-PID. These women will need additional mentoring and encouragement from AEC educators and professional organizations to strengthen their enthusiasm about the AEC profession. They should be assigned female AEC student, faculty, and professional mentors. Lastly, they should be encouraged to join AEC women student and professional organizations such as the National Association of Women in Construction (NAWIC) to increase their interactions with other AEC women communities.

The PROGRESSIVE category represents majority of the RPs (49.25\%). They did not have any AEC experiences, but shared some meaningful views about the AEC industry. They demonstrated the second highest level of nascent AEC-PID. Majority of RPs fell into this category and they are described as progressive because their lack of AEC experience does not hinder them from sharing their AEC views. Their limited AEC views are drawn from knowledge and understanding gained from the classroom, professors, peers, observations, books, student organizations, media, and the internet. Consequently, their comments are general statements about the growth, opportunities, collaboration, technology usage, and environmental aspects of the AEC industry; as well as regarding the lack of gender and racial diversity. One RP stated that 'I think that it (AEC industry) can get political especially dealing with environmental issues.' Another RP responded to the survey item after conducting an internet search on the AEC industry. This is commendable because she knew she did not have any AEC views, and went an extra mile to conduct some research on the AEC industry. In her own words, she stated that 'after doing some research on what the AEC industry was and what they offered, I was interested in the collaborative spirit within each of the groups to carry out and achieve a project larger than themselves separately.' RPs in this category expressed great enthusiasm about becoming AEC professionals and are excited about the changes that they would contribute to the AEC industry and profession. These women are ready to learn and progress in the profession. AEC professors and administrators should encourage these women to pursue internships in order to gain AEC experiences. They should also be encouraged to join AEC student clubs and organizations so that they can increase their knowledge and understanding of the AEC industry through interactions with other AEC students and professionals.

The PROACTIVE category represents RPs (28.36\%) with AEC views and AEC professional experiences. They demonstrated the highest nascent AEC-PID. They mostly gained access to industrial experience opportunities through teacher and family networks. As result of these experiences, some of these RPs shared specific personal experiences and observations of the AEC industry. An RP stated that 'I already know from an internship I did in my senior year of high school, I enjoy smaller offices because it is more personal and your ideas carry through.' Her comment provided her perspective of one critical decision students have to make when trying to select the best internship among several opportunities. Do I intern with smaller or larger organizations? Her statement is not a general statement as observed with RPs in the Progressive category. It is very specific and related to her learning experience during her internship. This prior AEC experience had shaped her views and strengthened her AEC-PID as indicated by her expressing that she did enjoy small offices and that her ideas are more likely to be implemented in that environment. This category provides the strongest nascent AEC-PID as the RPs identified strongly enough with the AEC profession to obtain professional experiences prior to even beginning their AEC undergraduate education. Furthermore, these RPs are not discouraged by 
the male-dominated environment that they experienced while working in the AEC industry, but have persisted to enroll in undergraduate AEC programs to become AEC professionals. With the highest nascent AEC-PID, women in the Proactive category should be given opportunities to serve as leaders in AEC classrooms and student organizations. Considering their AEC professional experience and enthusiasm, they should be encouraged to serve as peer mentors to other students, particularly AEC women. Lastly, they should be given the opportunity to step into more complex roles during internships and encouraged to pursue co-op opportunities.

Perfect Middle Ground: An in vivo code, Perfect Middle Ground, emerged as a key theme associated with several RPs committed to the quest to pursue a profession that required both STEM and Arts (STEAM) strengths. This is one of the distinct uniqueness of the AEC profession as it draws heavily from scientific and art disciplines as applied in the innovative and effective design and construction of buildings and infrastructure. One RP captured this theme beautifully in her statement that 'this major is the perfect middle ground because I can be creative, but still use my strong gift which happens to be math'. Approximately $11 \%$ of the RPs made similar direct statements regarding their preference for careers that will require them to utilize both their STEM (logic and facts) and Arts (creativity) strengths. A further examination of the favorite subjects confirmed that several RPs had multiple favorite subjects, with majority (52\%) falling into the STEAM category. They showed a strong preference for at least one STEM subject and fine Art, with $31.88 \%$ indicating that both math and art are their favorite subjects. They also enjoy sports, visual and performing arts activities (Figure 4). AEC communities should target girls who have strengths and preferences for STEAM subjects, particularly math and art. These girls are likely to have the strengths and passion needed to get enrolled in an undergraduate AEC program and successfully transition into the AEC profession. Beyond STEM pre-college programs, AEC educators should consider recruiting from sports, as well as visual and performing arts organizations for pre-college students (Figure 4).

\section{Conclusion}

As part of a longitudinal research project investigating AEC-PID processes in undergraduate AEC women in five participating U.S. institutions, this paper summarizes findings from the analysis of surveys completed by 69 AEC women. The key findings are as follows:

- Compared to construction management, AEC women are better represented in architecture and engineering programs;

- The characteristics of AEC women include preference for STEM and Art subjects, high GPAs, middle and high household income, medium-sized households, and some religious and political affiliations. They participate in extracurricular activities which are mostly physical, creative, hands on, and outdoor to include sports, dance, and AEC student organization activities;

- The in vivo code, Perfect Middle Ground, demonstrated the quest to combine math and fine art subject preferences in AEC career decisions;

- The four increasing levels of nascent AEC-PID categories (4Ps) are Plain, Passive, Progressive, and Proactive with majority of AEC women falling in the Progressive category and the Proactive category having women with the highest nascent AEC PID. Well-designed interventions can be effective in increasing the AEC-PID of women in each category; 
- Girls with STEAM strengths and passion, particularly in math and art are likely to develop AEC-PID. Beyond STEM programs, AEC educators should consider recruiting from sports, as well as visual and performing arts events for pre-college students;

- Undergraduate AEC women are aware of the importance of the AEC industry and its impact on the society, culture, and environment. However, they are concerned about the lack of gender and racial diversity.

Insights can guide AEC educators and administrators towards more targeted recruitment, mentoring, preparation, and retention interventions that strengthen AEC-PID and the persistence of the next generation of AEC women professionals. Specifically, findings can assist current and future AEC educators and administrators develop and modify academic programs, curricular, teaching methods, institutional environments, and best practices. Findings contribute to identity development and diversity theories that can guide AEC educational program and policy development and improve women representation in AEC professions. Future work involves investigating PID of these women as they transition from the freshman year into senior year, and then in to the AEC industry. In the long term, improved PID processes in AEC women students could improve their persistence; and, this would in turn reduce AEC workforce shortages, improve diversity in the AEC profession, and foster the innovation of gender friendly AEC products and services.

Acknowledgement: This material is based upon work supported by the National Science Foundation under Grant No. (NSF 1845979). Any opinions, findings, and conclusions or recommendations expressed in this material are those of the author(s) and do not necessarily reflect the views of the National Science Foundation. Support was also provided by Ms. Caroline Carpenter, the President of East Coast Construction Services and Executive Member of the Piedmont Chapter of the National Association of Women in Construction (NAWIC).

\section{References}

Association of American Colleges and Universities, "Facts and Figures: The income gaps in higher education enrollment and completion," AAC\&U News - Insights in Campus Innovations and Liberal Education, June/July 2018. [Online]. Available: https://www.aacu.org/aacunews/newsletter/2018/june/facts-figures [Accessed February 1, 2020].

D. Beijaard, P.C. Meijer, and N. Verloop, "Reconsidering research on teachers' professional identity," Teaching and Teacher Education, vol. 20, pp. 107 - 128, Feb. 2004.

N. Brickhouse, "Embodying science: A feminist perspective on learning," Journal of Research in Science Teaching, vol. 38, no. 3, pp. 282-295, Mar. 2001.

N. Brickhouse, K. Lowery, and K. Schultz. "What kind of girl does science? The construction of school science identities," Journal of Research in Science Teaching, vol. 37, no. 5, pp. 441-458, April 2000.

Building Design and Construction, "The talent shortage: Will the training the AEC industry desperately needs arrive in time?" 2016. [Online]. Available:

https://www.bdcnetwork.com/blog/talent-shortage-will-training-aec-industry-desperately-needsarrive-time [Accessed July 4, 2018] 
P. J. Burke, and J. E. Stets, Identity theory. New York, NY: Oxford University Press, Inc, 2009.

B. M. Capobianco, "Undergraduate women engineering their professional identities," Journal of Women and minorities in Science and Engineering, vol. 12, no. 2-3, pp. 95 - 117, Jan. 2006.

H.B. Carlone, "The cultural production of science in reform-based physics: Girls' access, participation, and resistance," Journal of Research in Science and Teaching, vol. 41, no. 4, pp. 392 - 414, March 2004.

K. Charmaz, Constructing grounded theory: A practical guide through qualitative analysis. California, US: Sage Publications, 2006.

K. Charmaz, Constructing grounded theory. $2^{\text {nd }}$ ed. Los Angeles CA: Sage. 2014.

P. Chinn, "Asian and Pacific Islander women scientists and engineers: A narrative exploration of model minority, gender, and racial stereotypes," Journal of Research in Science Teaching, vol. 39, no. 4, pp. $302-323$, Mar. 2002.

J. O. Choi, P. P. Shrestha, J. Lim, and B. K. Shrestha, "An investigation of construction workforce inequalities and biases in the Architecture, Engineering, and Construction (AEC) Industry," Construction Research Congress 2018, 2018.

M. Clarke, A. Hyde, and J. Drennan, "Professional identity in higher education," 2013.

[Online]. Available:

https://pdfs.semanticscholar.org/1e76/6cec71db82dea14f4f9de79e05af832789a0.pdf [Accessed

February 21, 2020]

R. L. Cruess, S. R. Cruess, and J. D. Boudreau, "A schematic representation of professional identity formation and socialization of medical student and residents: A guide for medial educators," Academic Medicine, vol. 90, no. 6, pp. 1 - 8, Mar. 2015.

J. P. Gee, "Identity as an Analytic Lens for Research in Education," Review in Research in Education, vol. 25, pp. $99-125,2000$.

B. Glaser and A. Strauss, The discovery of grounded theory. Chicago, IL: Aldine. 1967.

C. Groen, "Advancing from outsider to insider: A grounded theory of professional identity negotiation," $2017 . \quad$ [Online]. Available: https://vtechworks.lib.vt.edu/bitstream/handle/10919/77392/Groen_CJ_D_2017.pdf?sequence=1 [Accessed April 5, 2018].

C. Groen, M. C., Paretti, L., McNair, D. Simmons, and A. Shew, "Experiencing disability in undergraduate civil engineering education: An initial examination of the intersection of disability and professional identities" 2018 CoNECD - The Collaborative Network for Engineering and Computing Diversity Conference: Crystal City, Virginia, April 2018. 2018, pp. 1-14. 
C. Groen, D. R. Simmons, and L. D. McNair, "An introduction to grounded theory: Choosing and implementing an emergent method" 2017 ASEE Annual Conference \& Exposition, Columbus, Ohio, June 24 - 28, 2017. 2017, pp. 1-18.

Grounded Theory Online, "Ethical review proposals", 2018. [Online]. Available: from http://www.groundedtheoryonline.com/getting-started/ethical-review-irb/ [Accessed July 7, 2018]

D. M. Hatmaker, "Engineering Identity: Gender and professional identity negotiation among women engineers," Gender, Work and Organization, vol. 20, no. 4, pp. 382 - 396, July 2013.

J. Helms, "Science and me: Subject matter and identity in secondary science teachers," Journal of Research in Science Teaching, vol. 35, no. 7, pp. 811 - 834, Dec. 1998.

D., Holland, W., Lachiotte, D., Skinner, and C. Cain, Identity and agency in cultural worlds. Cambridge, MA: Havard University Press. 1998.

A. Kerby, Narrative and self. Bloomington, IN: Indiana University Press. 1991.

R. Kegan, The Evolving Self: Problem and Process in Human Development. Cambridge, MA: Harvard University Press. 1982.

M. Kogan, "Higher education communities and academic identity," Higher Education Quarterly, vol. 54, no. 3, pp. $207-216$, Dec 2000.

L. Kohlberg, The Psychology of Moral Development: The Nature and Validity of Moral Stages. San Francisco, CA: Harper \& Row. 1984.

Lexico, "Meaning of nascent in English," 2020. [Online]. Available:

https://www.lexico.com/en/definition/nascent . [Accessed February 3, 2020].

McGraw Hill Construction, "Construction industry: workforce shortages," (2012). [Online]. Available: https://www.usgbc.org/Docs/Archive/General/Docs18984.pdf [Accessed March 26, 2018].

National Association of Women in Construction, "Statistics," 2018. [Online]. Available from https://www.nawic.org/nawic/Statistics.asp. [Accessed February 2, 2020].

A. N. Ofori-Boadu, V. Ofori-Boadu, I. Borders-Taylor, L. Waller, and P. Akangah, "Professional Identity Formation and Development in HBCU Construction," Proceedings of the 2019 American Society for Engineering Education (ASEE) conference, Tampa, Florida, USA, June 16 $-19,2019,2019$, pp. 1-16.

A. N. Ofori-Boadu, D. Deng, C. Stevens, K. Gore, and I. Borders-Taylor, "Learning Experiences and Self-efficacy of Minority Middle-School Girls during a 'Bio-char Modified Cement Paste' Research Program at an HBCU," Proceedings of the 2019 American Society for Engineering Education (ASEE) conference, Tampa, Florida, USA, June 16 - 19, 2019, 2019, pp. 1-16. 
A. N. Ofori-Boadu, R. B. Pyle, I. Borders-Taylor, C. Bock-Hyeng, and T. Graham, “Advancing HBCU Students' Interests in Residential Construction Careers through an NAHB program: An Industry-University Collaboration," Proceedings of the 2019 American Society for Engineering Education (ASEE) conference, Tampa, Florida, USA, June 16 - 19, 2019, 2019, pp. 1-17.

A. N. Ofori-Boadu, "Improving Middle-School Girls' Self- Efficacy, Interests, and Knowledge in 'Sustainable Construction Engineering' through a STEAM ACTIVATED! Program," Proceedings of the 2018 American Society for Engineering Education (ASEE) conference, Salt Lack City, Utah, USA, June 24-27, 2018, 2018, pp. 1 - 21.

A. N. Ofori-Boadu, "Assessment of scientific literacy skills and attitudes of undergraduate construction management students," Proceedings of the 2018 American Society for Engineering Education (ASEE) conference, Salt Lack City, Utah, USA, June 24 - 27, 2018, 2018, pp. 1 - 11.

A. N. Ofori-Boadu, M. A. Shofoluwe, R. Kelley, E. R. Sowells, and R. B. Pyle, "Assessing the impact of an industry-led professional development workshop on the $21^{\text {st }}$ century 'soft' skills of CM students at an HBCU," Proceedings of the 2017 American Society for Engineering Education (ASEE) conference, Columbus, Ohio, USA, June 25 - 28, 2017, 2017, pp. 1 - 17.

A. Phipps, "Engineering Women: The 'Gendering' of professional identities," Int. J. Engng. Ed., vol. 18, no. 4, pp. 409-414, June 2002.

J. Piaget and B. Inhelder, The Psychology of the Child. New York, NY: Basic Books. 1969.

D. Porter and A. N. Ofori-Boadu, "Examination of future construction career role preferences and identities of construction students," Proceedings of the 2018 American Society for Engineering Education (ASEE) conference, Salt Lack City, Utah, USA, June 24 - 27, 2018, 2018, pp. 1 - 15.

Statista, "Distribution of households in the United States from 1970 to 2019 by household size," 2020. [Online], Available: https://www.statista.com/statistics/242189/disitribution-ofhouseholds-in-the-us-by-household-size/ [Accessed February 1, 2020].

United States Department of Labor, "Industry at a glance," 2018. [Online]. Available: https://www.bls.gov/iag/tgs/iag23.htm [Accessed June 21, 2018]

United Nations Educational, Scientific and Cultural Organization, "Cracking the code: Girls' and women's education in science, technology, engineering, and mathematics (STEM)," Education 2030. 2017. [Online]. Available: http://unesdoc.unesco.org/images/0025/002534/253479e.pdf [Accessed May 15, 2018]

V.L.Vignoles, S.J. Schwartz, and K. Luyckx, “Toward an integrative view of identity,” In: Schwartz, S.J., Luyckx, K., \& Vignoles, V.L., eds. Handbook of Identity Theory and Research. New York, NY: Springer. 2011. 